Eduardo Algranti'

José Marçal Jackson Filho

Eduardo Garcia Garcia ${ }^{2}$

Aparecida Mari Iguti ${ }^{3}$

Carlos Machado de Freitas ${ }^{3}$

José Prado Alves Filho ${ }^{3}$

Marco Antonio Bussacos ${ }^{3}$

Mina Kato ${ }^{3}$

Rodolfo Andrade de Gouveia Vilela ${ }^{3}$

Rose Alyce Oliveira Leite ${ }^{3}$

\footnotetext{
${ }^{1}$ Editores científicos

${ }^{2}$ Editor executivo

${ }^{3}$ Editores associados
}

\section{A RBSO e seu compromisso com o campo da Saúde do Trabalhador}

\author{
RBSO and its commitment to Workers' Health
}

A Revista Brasileira de Saúde Ocupacional (RBSO) apresenta-se como um veículo pioneiro e singular de difusão científica no Brasil dedicada a questões que envolvem o trabalho, a saúde e o ambiente, refletindo uma visão integrada da saúde dos trabalhadores.

Ao mesmo tempo em que se constitui em um patrimônio histórico da construção social do próprio campo da Segurança e Saúde do Trabalhador (SST) pelos seus 36 anos de existência, a RBSO se atualiza e vem se renovando intensamente, adquirindo novos significados. A partir da edição de número 114 de dezembro de 2006, quando se deu o início do seu processo de revitalização, esta tendência vem se reafirmando por meio da ampliação do escopo da revista e da publicação de trabalhos de origens multi e interdisciplinares, com abordagens diversificadas, assegurados o rigor científico necessário, a relevância social dos textos e a regularidade da publicação.

Para muitos dos estudiosos envolvidos neste tema, a expressão "Saúde Ocupacional” não é suficiente para representar o campo coberto pela RBSO e parece limitada para acompanhar a evolução conceitual das áreas e interfaces do conhecimento em SST, a problemática tratada pelo campo, bem como as transformações paradigmáticas ocorridas na ciência. Não seria, então, o momento de atender ao apelo desses vários profissionais, pesquisadores e especialistas propondo um novo nome para a revista? Caso contrário, quais são as razões que justificam a sua manutenção?

A despeito do crescimento da produção acadêmica no campo da Saúde do Trabalhador, Carlos Minayo Gomes e Francisco Lacaz (Saúde do trabalhador: novas-velhas questões. Ciência \& Saúde Coletiva, Rio de Janeiro, v. 10, n. 4, p. 797-807, 2005), ao analisarem as dificuldades e as barreiras à implementação das políticas públicas em Saúde do Trabalhador no SUS, indicaram a "fragmentação e dispersão da produção científica da área” como fator determinante. A política editorial da RBSO visa, portanto, enfrentar esse aspecto apontado, colocando-se como um lócus da produção acadêmica na área. Para a consolidação deste propósito, são necessários registros em bases de indexação de reconhecida importância nos cenários nacional e internacional, sobretudo na SciELO, assim como melhores avaliações no sistema Qualis/Capes, firmando-se como uma opção atraente para submissão de trabalhos.

Neste contexto, a mudança de nome implicaria num distanciamento das metas de inclusão da RBSO na SciELO e em outras bases internacionais, em curto e médio prazos, pela perda da continuidade dos dados bibliométricos das suas citações referentes a todas as edições anteriores. No caso da SciELO, 
somente após a publicação de quatro números com um novo título seria possível a submissão para avaliação como um novo periódico. Considerando a periodicidade atual, esta opção significaria uma espera mínima de dois anos, com o agravante de que a mudança de nome poderia desmerecer toda a história da revista, duramente construída e que a consolidou como um importante referencial de informações científicas em SST.

A decisão tomada pelo corpo editorial foi pela manutenção do atual nome da revista, assegurando a qualidade dos trabalhos publicados, agregando novos referenciais teóricos, conceituais e metodológicos, incorporando a abordagem interdisciplinar, aperfeiçoando a política editorial e o gerenciamento interno da revista, garantindo fontes de financiamento adequado às exigências do processo editorial e melhorando a acessibilidade e a divulgação do periódico junto à comunidade científica e à sociedade.

Desta forma, a RBSO busca consolidar seus objetivos e cumprir a missão de "publicar artigos científicos relevantes para o desenvolvimento do conhecimento e para incrementar o debate técnico-científico no campo da SST”, contribuindo, de forma substancial, para o avanço do conhecimento científico e para a elaboração de políticas públicas e privadas em prol da saúde dos trabalhadores. 